\title{
Determination of Hepatıtıs E Vırus Infection Frequency and Risk Factors in Viral Hepatites in Diyarbakır Regıon
}

\section{Songül Beskisiz ${ }^{1}$, Omer Satici ${ }^{2}$, Vatan Kavak ${ }^{3 *}$ and Kendal Yalcin ${ }^{4}$}

${ }^{1}$ Department of Internal Medicine, Gazi Yaşargil Training and Research Hospital,

University of Health Sciences, Diyarbakir, Turkey

${ }^{2}$ Department of Bitoistatics, Faculty of Medicine, Dicle University, Diyarbakir,

Turkey

${ }^{3}$ Department of Anatomy, Faculty of Medicine, Dicle University, Diyarbakir, Turkey

${ }^{4}$ Department of Hepatology, Faculty of Medicine, Dicle University, Diyarbakir,

Turkey

*Corresponding Author: Vatan Kavak, Department of Anatomy, Facultey of

Medicine, Dicle University, Diyarbakir, Turkey.
Received: May 18, 2021

Published: June 30, 2021

(C) All rights are reserved by Vatan Kavak., et al.

\section{Abstract}

Aim: Our aim in this study; Liver in the domain of hepatitis E virus infection; It is the largest organ in the body located in the upper right of the abdominal cavity. The liver organ is the organ in the domain of the hepatitis E virus. It is to retrospectively investigate the HEV seropositivity in patients with viral hepatitis who are 18 years of age and older who applied to Dicle University Faculty of Medicine, Department of Gastroenterology, and to determine the risk factors associated with HEV infection by evaluating the cases according to epidemiological, clinical and laboratory characteristics.

Material and Methods: Within the scope of this study, 1025 patients aged 18 and over who applied to Dicle University Faculty of Medicine Gastroenterology Department between May 2011 and March 2015 were included. Age, gender, biochemistry (ALT, AST, GGT, Total bilirubin, albumin), whole blood (hemoglobin, thrombocyte), coagulation (INR), demographic criteria (origin (urban/ rural), educational status (primary school and below-low, middle school and above-high), marital status (married/single), pregnancy (yes/no), known family history of viral hepatitis (yes/no), contact with animals, substance abuse (yes/no), alcohol use (yes/no no), cirrhosis status (yes/no), time of infection in patients with viral hepatitis, and antiviral drug use were retrospectively investigated.

Statistical Analysis: The data were transferred from the Excel package program to the SPSS (Statistical Package for Social Sciences) 25 package program. Variables were defined as categorical, ordered, and continuous measurement variables, and appropriate tests were used for these variables.

Results: The mean age of the patients was $49.29 \pm 15.39$ years and Anti-HEV IgG seropositivity was determined $56,4 \%$ of all patients (578/1025). HEV seropositivity was 76,3\% in patients with HCV (29/38), 50\% in patients with HBV (142/284), 70,7\% in patients with HDV (58/82) and 56.2\% in control group (349/621). Highest mean age in the groups was detected in HCV patients as 51.84 \pm 15.77 years $(\mathrm{P}=0.001$ ). Rate of Anti-HEV IgG seropositivity according to age groups was highest in patients older than 61 years old (141/578, 24.4\%) and lowest in patients between 18-30 years old (68/578, 11.8\%) $(\mathrm{P}<0.001)$. Advanced age, rural origin, low education level, being married, history of contact with animals, high ALT levels, high GGT levels, low platelet levels, anti-delta sero- 
seropositivity, ani-HCV seropositivity and anti-HAV IgG seropositivity was found to be significant risk factors for HEV seropositivity in the logistic regression analysis.

Conclusion: In this study, it was found that HEV infection is more common in people with low education levels in our region, people living in rural areas, elderly people, married people, those who are engaged in animal husbandry, and cirrhotic patients. In addition, ALT and GGT elevation, low platelets, anti-delta positive, anti-HCV positive and anti-HAV IgG positive were determined as risk factors for seropositivity in logistic regression analysis. These demographic findings may contribute to the determination of risky patients and taking preventive measures in the control of HEV infection. Accurate and permanent anatomy education provides the ability to comment $85 \%$ on all diseases. Therefore, in studies belonging to researchers; anatomy is important.

Keywords: Hepatitis E Virus; Hepatitis B Virus; Hepatitis C Virus; Hepatitis D Virus; Etiology; Epidemiology; Liver Anatomy

\section{Introduction}

Liver in the domain of hepatitis E virus infection; It is the largest organ in the body located in the upper right of the abdominal cavity. The liver - hepar - is the largest gland in the body, dark reddish-brown in color, its weight is about $1,5 \mathrm{~kg}$. The liver has several functions. The main is the digestive function - the liver acts as an exocrine gland in respect of production of the bile. The liver also has a barrier function and a phagocytic function. The liver is involved in thermoregulation and in carbohydrate, protein and fat metabolisms. The liver produces the erythrocytes in the foetal period of the life.

Anteriorly the liver has a thin and sharp inferior border projected downward - margo inferior. The posterior part is round in shape and not covered by the peritoneum (bare area) - area nuda. There are two surfaces:

Facies diaphragmatica - is superior convex surface projected toward the diaphragm; there is a ligament - ligamentum falciforme - which separates right and left lobes of the liver - lobus hepatis dexter et lobus hepatis sinister, the right lobe is much larger than the left.

Facies visceralis - is directed downward towards the abdominal organs. There are four lobes separated by grooves on the visceral surface of the liver. The right sagittal groove separates the right lobe from the rest of the lobes. The left sagittal groove separates left lobe from the rest of the lobes. The transverse groove is between the sagittal grooves; it separates the quadrate lobe - lobus quadratus anteriorly from the caudate lobe - lobus caudatus - posteriorly. The porta hepatis (the entrance of the liver) - porta hepatis - is situated in transverse groove. It contains ductus hepaticus communis, vena portae hepatis, arteria hepatica propria, nerves and lymph vessels.

There are different formations localized in the sagittal grooves. There is a fossa for gallbladder - fossa vesicae biliaris (felleae) with the gall bladder in the anterior part of the right sagittal groove. There is a groove for vena cava - sulcus venae cavae - with vena cava inferior posteriorly. In the anterior part of the left sagittal groove there is fissura ligamenti teretis with ligamentum teres hepatis in it (before the birth the ligament is umbilical vein); in the posterior part of the left sagittal groove fissura ligamenti venosi with ligamentum venosum in it (before the birth it is a blood vessel).

Tunica fibrosa and tunica serosa (peritoneum) cover the liver. The peritoneum covers the liver from three sides; the peritoneum does not cover the bare area and the grooves on the visceral surface of the liver.

Tunica serosa (the peritoneum) forms the ligaments for the attachment of the liver to the adjacent organs.

Ligaments are of two groups:

Ligaments extending to the diaphragm:

- Ligamentum falciforme - it is situated in the sagittal plane between the diaphragm and the upper surface of the liver; in its anterior free border lies ligamentum teres hepatis (obliterated umbilical vein, which extends from the porta hepatis to the umbilical ring),

- Ligamentum coronarium - is situated in the frontal plane and extends from the bare area to the diaphragm; 
Ligaments extending from the porta hepatis toward the organs:

- Ligamentum hepatogastricum - to the lesser curvature of the stomach,

- Ligamentum hepatoduodenale - to the superior portion of the duodenum,

- Ligamentum hepatorenale - to the right kidney.

\section{Topography of liver}

Holotopia is in regio hypochondriaca dextra, regio epigastrica and regio hypochondriaca sinistra.

Skeletotopia: the upper border on the right side reaches the intersection of linea medioclavicularis dextra and the $4^{\text {th }}$ intercostal space, then it turns downward to the left $5^{\text {th }}$ intercostal space. The course of the lower border starts on the right side at the intersection of linea axillaris media and the $10^{\text {th }}$ rib, then it curves along the costal arch to the junction point between the cartilages of the $9^{\text {th }}$ and $8^{\text {th }}$ ribs. The border crosses regio epigastrica and reaches the left side, where the cartilage of the 8th rib joins with the cartilage of the $7^{\text {th }}$ rib; the lower border ends at the level of the $6^{\text {th }}$ intercostal space. Posteriorly the liver corresponds between the $9^{\text {th }}$ and $11^{\text {th }}$ thoracic vertebrae.

Syntopia: the diaphragmatic surface faces to the heart what makes a cardiac depression from it on the left lobe (impressio cardiaca); the visceral surface has depressions of the oesophagus (impressio oesophageale), the stomach (impressio gastrica), the duodenum (impressio duodenalis), the colon (impressio colica), the right kidney (impressio renalis) and the right suprarenal gland (impressio suprarenalis).

The bile pathway is illustrated in figure 1.

The bile is produced by the liver uninterruptedly and excreted through right and left hepatic ducts - ductus hepaticus dexter et sinister. They join at the porta hepatis to form the common hepatic duct - ductus hepaticus communis. The common hepatic duct joins with the cystic duct - ductus cysticus - from the gallbladder to form the bile duct - ductus choledochus (biliaris).

The gallbladder - vesica biliaris (fellea) - is a conical or pear-shaped organ for storage of the bile, lodged in the fossa for gallbladder on the visceral surface of the right lobe of the liver. Its capacity is about $40-60 \mathrm{~cm}^{3}$. It has the fundus of gallbladder - fundus vesicae biliaris (felleae) - directed forward to the inferior hepatic border, the body of gallbladder - corpus vesicae biliaris (felleae) - and the neck of gallbladder - collum vesicae biliaris (felleae). The neck of the gallbladder continues into the cystic duct; the duct is about 3,5 $-4,5 \mathrm{~cm}$ long.

The bile duct is formed by the union of two ducts: the cystic duct and the common hepatic duct. It is about $7 \mathrm{~cm}$ long and it drains the bile into the duodenum. The bile duct runs along ligamentum hepatoduodenale together with vena portae, arteria hepatica propria, then crosses the superior part of the duodenum from behind, passes between the descending part of the duodenum and the head of the pancreas, pierces the posterior wall of the descending part of the duodenum forming a longitudinal fold - plica longitudinalis duodeni. At its termination the bile duct unites with the pancreatic duct - ductus pancreaticus - to form the hepatopancreatic ampulla - ampulla hepatopancreatica (biliaropancreatica), which opens by a common orifice upon papilla duodeni major.

The wall of the gall bladder and the bile duct is formed of three layers: tunica mucosa, tunica muscularis and tunica serosa or tunica adventitia. The mucous membrane lines the gallbladder and forms the mucosal folds. There is a spiral fold - plica spiralis - at the cystic duct. Mucous glands are scattered in the mucosa of the gallbladder and bile duct.

The muscular coat is in one circular layer, which at the region of ampulla hepatopancreatica forms a sphincter - musculus sphincter ampullae, which opens only at the time of digestion. The serous coat (the peritoneum) covers the gallbladder from lower surface; tunica adventitia covers the upper surface (which lies in the fossa of the gallbaldder). The anatomical structure and organ neighborhoods of the liver affected by the hepatitis E virus should be known. Researchers emphasize the importance of the anatomical structure of the liver [1].

Hepatitis E virus (HEV) is an RNA virus with a size of 27-34 nm, non-enveloped, icosahedral structure, single stranded and positive polarity. Hepatitis $\mathrm{E}$ virus is the second most common cause of fecal-orally transmitted hepatitis after hepatitis A virus (HAV). Hepatitis clinic caused by hepatitis $E$ virus can be seen in a spectrum ranging from an asymptomatic picture to fulminant disease.

Its prevalence in the world is closely related to economic development, and its frequency varies greatly depending on factors such 
as geographical region, socioeconomic level and age. Seropositivity rates have been shown to be between 1 and 20\% in developed countries [2]. Studies in our country have shown that the HEV seroprevalence is between $3.5-73 \%$ [3].

Hepatitis $\mathrm{E}$ is an infection that causes inflammation of the liver tissue and changes in the anatomical structure of the liver. Viral hepatitis, one of the oldest diseases in human history, was first recorded in medical records by Hippocrates. The first scientific definition of the disease was made in 1865 by the famous pathologist Virschow as "catarrhal icter". II. The emergence of different clinical pictures in the outbreak of jaundice seen in soldiers during World War II, it has been thought that more than one factor may be responsible for viral hepatitis pictures. With the discovery of Blumberg's hepatitis B virus antigen in 1963, it became certain that there were more than one hepatitis agent and developments regarding viral hepatitis were accelerated.

\section{Aim of the Study}

It is to retrospectively investigate the HEV seropositivity in patients with viral hepatitis who are 18 years of age and older who applied to Dicle University Faculty of Medicine, Department of Gastroenterology, and to determine the risk factors associated with HEV infection by evaluating the cases according to epidemiological, clinical and laboratory characteristics.

\section{Material and Method}

Within the scope of this study, 1025 patients aged 18 and over who applied to Dicle University Faculty of Medicine Gastroenterology Department between May 2011 and March 2015 were included. Age, gender, biochemistry (ALT, AST, GGT, Total bilirubin, albumin), whole blood (hemoglobin, thrombocyte), coagulation (INR), demographic criteria (origin (urban/rural), educational status (primary school and below-low, middle school and above-high), marital status (married/single), pregnancy (yes/no), known family history of viral hepatitis (yes/no), contact with animals, substance abuse (yes/no), alcohol use (yes/no no), cirrhosis status (yes/no), time of infection in patients with viral hepatitis, and antiviral drug use were retrospectively investigated.

The subjects included in the study were divided into four groups. All patients with different clinical forms who are HbsAg positive HBV group, patients with anti-delta positive HDV group, patients with anti-HCV positive HCV group, patients with HBsAg, anti-HCV and anti-delta negative who are followed up in outpatient and inpatient clinics in gastroenterology outpatient clinics and clinics. It was defined as the control group.

For the determination of Anti-HEV IgG and IgM, a commercial microELISA kit (Triturus device-Grifols company, Italy) standardized in the central laboratory of our hospital was used.

HBsAg, anti-HBs, HBeAg, anti-HBe, anti-HBc IgG and anti-HCV examinations were carried out in the Microbiology laboratory of our hospital with the MacroEIA method in the Cobas e 601 device of Roche company (ELECSYS 2010, Roche Diagnostics GmbH, D-68298 Mannheim, Germany). Worked with original kits. AntiHDV total level was studied with Triturus model of Grifols brand with microelisa method.

\section{Whole blood}

The CELL-DYN 3700 device (Abbott-America) in the EDTA tube was used to measure an average of 3 counts with an automatic optical laser impedance system.

ALT, AST, GGT, albumin, total bilirubin; The Architect C 16000 device (USA) was studied using the enzymatic method in a gel biochemistry tube.

The anatomy and organ neighborhoods of the liver organ affected by the hepatitis E virus were detailed in this study.

Statistical analysis; The data were transferred from the Excel package program to the SPSS (Statistical Package for Social Sciences) 25 package program. Variables were defined as categorical, ordered, and continuous measurement variables, and appropriate tests were used for these variables. Student's t-test was used to compare two independent groups. Chi-square test was used for categorical variables determined by counting. One-way analysis of variant (one-way ANOVA) was used to compare more than two groups. Post-hoc comparison tests were used to determine the important group mean. Multivariate analysis was performed using logistic regression test to determine risk factors. P values $<0.05$ were considered significant.

\section{Results}

The results of our age-specific seroprevalence study of anti-HEV IgG seropositivity according to the groups were: HBV: $18,12.7 \%$ in the $18-30$ age group, $41,11.7 \%$ in the control group, $\mathrm{P}<0.001$ (Ta- 


\begin{tabular}{|l|c|c|}
\hline \multicolumn{1}{|c|}{ Age groups } & HBV & Control \\
\hline $18-30$ & $18, \% 12.7$ & $41, \% 11.7$ \\
\hline $31-40$ & $39, \% 27.5$ & $63, \% 18.1$ \\
\hline $41-50$ & $33, \% 23.2$ & $69, \% 19.8$ \\
\hline $51-60$ & $31, \% 21.8$ & $74, \% 21.2$ \\
\hline$>61$ & $21, \% 14.8$ & $102, \% 29.2$ \\
\hline P Value & $\mathrm{P}<0.001$ & $\mathrm{P}<0.001$ \\
\hline
\end{tabular}

Table 1: Age-specific seroprevalence of anti-HEV IgG seropositivity by groups $(\mathrm{n}, \%)$.

ble 1). By age groups to follow; HBV: 39, \%27.5, Control: $63, \% 18.1$ in the 31-40 age group. HBV: 33, \% 23.2, Control: $69, \% 19.8$ in the 41-50 age. HBV: 31, \%21.8, Control: 74, \%21.2 in the 51-60 age group. HBV: 21, \%14.8, Control: 102, \%29.2 in the >61 age group (Table 1).

\begin{tabular}{|c|c|c|c|}
\hline & \multicolumn{2}{|c|}{ Anti-HEV IgG (+) Anti-HEV IgG (-) } & \multirow{2}{*}{ P Value } \\
\hline & $(n=578)$ & $(n=447)$ & \\
\hline Age (years) & $49.29 \pm 15,39$ & $36,79 \pm 15,44$ & $\mathrm{P}<0.001$ \\
\hline $\begin{array}{l}\text { Urban/rural } \\
\text { (urban,\%) }\end{array}$ & $253(\% 46)$ & $297(\% 54)$ & $\mathrm{P}<0.001$ \\
\hline $\begin{array}{l}\text { Education level } \\
(\text { low,\%) }\end{array}$ & 305 (\% 72.8) & $114(\% 27.2)$ & $\mathrm{P}<0.001$ \\
\hline $\begin{array}{l}\text { Marital status } \\
\text { (married,\%) }\end{array}$ & $463(\% 61.4)$ & $290(\% 38.6)$ & $\mathrm{P}<0.001$ \\
\hline Pregnancy (yes,\%) & $10(\% 24.4)$ & $31(\% 75.6)$ & $\mathrm{P}<0.001$ \\
\hline $\begin{array}{l}\text { History of } \\
\text { contact with } \\
\text { animals (yes,\%) }\end{array}$ & $260(\% 72.6)$ & $98(\% 27.4)$ & $\mathrm{P}=0.001$ \\
\hline $\begin{array}{l}\text { Cirrhosis presence } \\
(\text { Yes, } \%)\end{array}$ & $115(\%$ 69.2) & $51(\% 30.8)$ & $\mathrm{P}<0.001$ \\
\hline $\begin{array}{l}\text { Antiviral treatment } \\
\text { intake (Yes,\%) }\end{array}$ & $166(\% 62.6)$ & $99(\% 37.4)$ & $\mathrm{P}=0.01$ \\
\hline \multicolumn{4}{|c|}{ Laboratory parameters of all cases } \\
\hline ALT, U/L & $102.96 \pm 298.76$ & $157.46 \pm 433.20$ & $\mathrm{P}<0.01$ \\
\hline Hemoglobin, g/dl & $12.49 \pm 2.54$ & $13.09 \pm 4.04$ & $\mathrm{P}<0,01$ \\
\hline Trombosit, K/uL & $\begin{array}{c}217432.56 \pm \\
110303.89\end{array}$ & $\begin{array}{c}234580.72 \pm \\
102067.73\end{array}$ & $\mathrm{P}<0,01$ \\
\hline
\end{tabular}

Table 2: Epidemiological and clinical characteristics of all cases

$$
(n, \%) \text {. }
$$

Epidemiological and clinical features of all cases included in our study (Table 2) are seen.

The results of the comparison of epidemiological and clinical characteristics between the age groups that we have included in the study (Table 3) are as shown.

Logistic regression analysis of the factors affecting Anti-HEV IgG positivity (Table 4) is seen in the light of the findings we examined within the scope of the study.

Visual drawing of the liver anatomy and portal circulation in the domain of the hepatitis E virüs [1].

\section{Discussion and Conclsuion}

Hepatitis E virus infection is encountered in two forms, epidemic and sporadic, in the world. While HEV infection causes epidemics in many regions of the world, especially in countries where environmental sanitation and hygiene conditions are insufficient, it occurs sporadically in developed western countries with a high socioeconomic level, sufficient infrastructure [2,10,25,31,42]. Although the main transmission route is the fecal-oral route, it is a fact accepted today that HEV infections have zoonotic properties.

HEV seroprevalence in developing countries; $17.2 \%$ in Egypt, 8.4\% in Saudi Arabia, 33\% in Yemen, 15.7\% in Thailand, 50\% in India, 16-31\% in Nepal, and 78\% in Somalia (34.91). (92.93). On the other hand, HEV seroprevalence is lower in developed countries and it is reported as $2.1 \%$ in the USA, $0.4 \%$ in Australia, 3.9\% in England, 5.5\% in Spain and 2.2\% in Greece [26,31,47].

In our country, in studies on HEV seroprevalence, the general seropositivity rate is reported as approximately 6\%; however, this rate varies according to the regions where the study was conducted, age groups and case groups. In these studies covering various regions in our country, rates varying between $3.5 \%$ and $73 \%$ are reported (Table 1).

In the study conducted by Thomas., et al. The frequency of anti-HEV was found to be $5.9 \%$ in sera collected from five different regions of Turkey, and they evaluated Turkey among the regions where hepatitis E is seen as endemic [3].

With this study, it was aimed to retrospectively investigate the HEV seropositivity in viral patients aged 18 years and older who 


\begin{tabular}{|c|c|c|c|c|c|}
\hline & $\begin{array}{c}\text { HBV } \\
(n=284)\end{array}$ & $\begin{array}{c}\text { HDV } \\
(\mathrm{n}=\mathbf{8 2})\end{array}$ & $\begin{array}{c}\text { HCV } \\
(n=38)\end{array}$ & $\begin{array}{l}\text { Non-viral } \\
(n=621)\end{array}$ & $P$ value \\
\hline Age (years) & $40.39 \pm 14.77$ & $44.98 \pm 13.92$ & $51.84 \pm 15.77$ & $44.78 \pm 17.47$ & $P=0.001$ \\
\hline Gender (male, \%) & $\% 67.2$ & $\% 73.1$ & $\% 55.2$ & $\% 47.3$ & $P=0.001$ \\
\hline Education level (low,\%) & $\% 37.9$ & $\% 55.1$ & $\% 54.5$ & $\% 49.6$ & $P=0.007$ \\
\hline $\begin{array}{l}\text { Hepatitis history in the family } \\
\text { (yes,\%) }\end{array}$ & $\% 69.5$ & $\% 85.7$ & $\% 19.3$ & $\% 12.7$ & $P=0.001$ \\
\hline Contact with animals (yes,\%) & $\% 35.5$ & $\% 56.5$ & $\% 46.8$ & $\% 40.7$ & $P=0.01$ \\
\hline Substance intake history (yes,\%) & $\% 2.9$ & $\% 7.2$ & $\% 6.06$ & $\% 1.6$ & $P=0.02$ \\
\hline Alcohol use history (yes,\%) & $\% 18.9$ & $\% 21.8$ & $\% 33.4$ & $\% 9.1$ & $\mathrm{P}=0.001$ \\
\hline Cirrhosis presence (Yes,\%) & $\% 14.4$ & $\% 67.5$ & $\% 34.2$ & $\% 9.4$ & $P=0.001$ \\
\hline Antiviral treatment intake (Yes,\%) & $\% 63.9$ & $\% 82.4$ & $\% 58.8$ & $\% 3.3$ & $P=0.001$ \\
\hline Anti-HEV IgG (+) & $\% 50$ & $\% 70.7$ & $\% 76.3$ & $\% 56.2$ & $P=0.001$ \\
\hline \multicolumn{6}{|c|}{ Laboratory parameters belonging to the groups } \\
\hline ALT, U/L & $214.71 \pm 543.65$ & $105.91 \pm 303.48$ & $50.84 \pm 51.91$ & $93.88 \pm 259.09$ & $P=0.001$ \\
\hline AST, U/L & $151.90 \pm 389.92$ & $112.90 \pm 338.37$ & $48.79 \pm 39.94$ & $81.06 \pm 275.78$ & $P=0.01$ \\
\hline Albumin, g/dl & $3.76 \pm 0.74$ & $3.51 \pm 0.81$ & $3.27 \pm 0.84$ & $3.44 \pm 0.78$ & $\mathrm{P}=0.001$ \\
\hline Total bilirubin, mg/dl & $1.88 \pm 3.81$ & $2.46 \pm 4.53$ & $1.42 \pm 1.22$ & $1.44 \pm 2.84$ & $P=0.03$ \\
\hline Hemoglobin, g/dl & $13.88 \pm 2.42$ & $13.1 \pm 2.40$ & $12.18 \pm 2.83$ & $12.21 \pm 3.62$ & $P=0.001$ \\
\hline Trombosit, K/uL & $\begin{array}{c}222155.7 \pm \\
78306.4\end{array}$ & $\begin{array}{c}170222.2 \pm \\
121939.5\end{array}$ & $\begin{array}{c}165201.05 \pm \\
68056.8\end{array}$ & $\begin{array}{c}237049.8 \pm \\
114709.2 \\
\end{array}$ & $P=0.001$ \\
\hline PTT, INR & $1.06 \pm 0.26$ & $1.18 \pm 0.24$ & $1.15 \pm 0.27$ & $1.08 \pm 0.32$ & $P=0.01$ \\
\hline
\end{tabular}

Table 3: Comparison of epidemiological and clinical characteristics between groups.

\begin{tabular}{|l|c|c|}
\hline & $\begin{array}{c}\text { University } \\
\text { OR (95 CI) }\end{array}$ & P Value \\
\hline Age ( $>35$ and $\leq 35$ years) & $1.77(1.61-1.95)$ & $\mathrm{P}<0.001$ \\
\hline Education level (low/high) & $0.25(0.19-0.33)$ & $\mathrm{P}<0.001$ \\
\hline Pregnancy (yes/no) & $0.25(0.11-0.52)$ & $\mathrm{P}<0.001$ \\
\hline Contact with animals (yes/no) & $3.33(2.49-4.45)$ & $\mathrm{P}<0.001$ \\
\hline ALT, U/L (35 and above) & $0.75(0.58-0.97)$ & $\mathrm{P}=0.02$ \\
\hline $\begin{array}{l}\text { Platelet, K/uL (150000 and } \\
\text { below) }\end{array}$ & $0.55(0.4-0.74)$ & $\mathrm{P}<0.001$ \\
\hline Anti-delta positivity (yes/no) & $1.91(1.17-3.1)$ & $\mathrm{P}=0.009$ \\
\hline Anti-HCV positivity (yes/no) & $2.47(1.19-5.1)$ & $\mathrm{P}=0.01$ \\
\hline Anti-HAV IgG positive (yes/no) & $10.55(1.31-$ & $\mathrm{P}=0.02$ \\
\hline
\end{tabular}

Table 4: Logistic regression analysis of factors affecting anti-HEV IgG positivity.

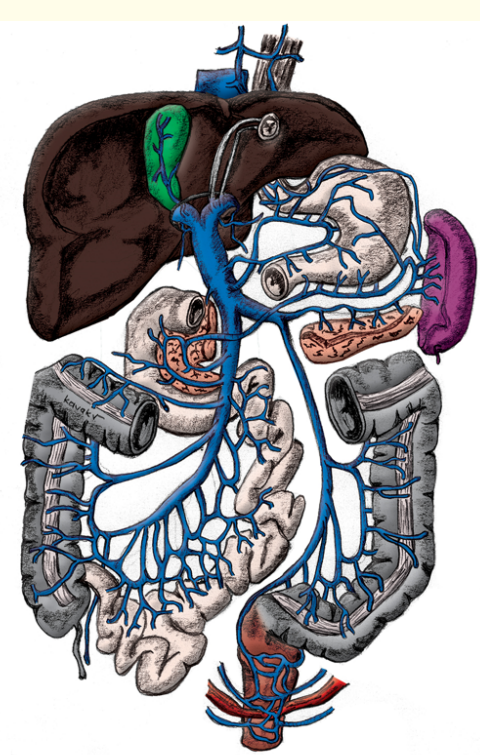

Figure 1: Liver and portal circulation. This drawing was drawn by Anatomy painter Prof. Dr. Vatan Kavak. 
applied to Dicle University Faculty of Medicine, Department of Gastroenterology, to evaluate the epidemiological, clinical and laboratory characteristics of the cases and to reveal the factors affecting HEV infection seropositivity. In addition, it was aimed to determine the risk factors associated with HEV infection in our region.

In the study we conducted for this purpose, the total anti-HEV IgG seropositivity rate was found to be $56.4 \%$ (578/1025) in all patient groups. These results are from previous studies both in Diyarbakır; It was observed that anti-HEV seropositivity was higher than the studies conducted in other regions in Turkey [3]. One of the main reasons for this situation may be that unlike other studies, a patient group with viral hepatitis was studied in our study.

Anti-HEV seropositivity; It was seen in 50\% (142/284) of HBV patients, 70.7\% (58/82) in HDV patients, 76.3\% (29/38) in HCV patients, and $56.2 \%(349 / 621)$ in the non-viral group ( $\mathrm{p}=0.001)$. Seropositivity in the non-viral group was similar to the rate in our entire study population. The high rate in patients with HCV may be related to the older age in this patient group.

In our study, the mean age of the patients was found to be 49.29 \pm 15.39 years. Average age in groups; It was observed that it was the lowest with $40.39 \pm 14.77$ years in HBV and the highest with $51.84 \pm 15.77$ years in HCV $(p=0.001)$. It was observed that antiHEV IgG seroprevalence increased with age (Table 1). When all these data are analyzed together; It can be stated that HEV-IgG antibodies start to become positive in young adults, increase in adults and reach the highest level in advanced ages ( $p<0.001)$. These data showing that anti-HEV IgG seroprevalence increases with age are similar to the results of other studies conducted in our country [3]. In the HEV-IgG seroprevalence study of Thomas et al. Covering the provinces of Istanbul, Adana, Aydın, Ayvalık and Trabzon; HEV seropositivity was determined with a rate of $2.3 \%$ under the age of $26,6.2 \%$ between the age of $26-54$ and $8.5 \%$ above the age of 54 , and the difference between age groups was reported to be significant [3].

In our study, anti-HEV IgG positivity was found in 58\% of men and $54.5 \%$ of women ( $p=0.26)$. Studies in the world and in our country show that the HEV seroprevalence is similar between genders. Khuroo et al. Found the male/female ratio as $1.4 / 1$ in their study in India. In the study conducted by Wong et al. In Hong Kong, the rate of seropositivity was found to be $18.4 \%$ in men and $19.1 \%$ in women [48].

In our study, anti HEV IgG positivity was found in $70.9 \%$ $(249 / 351)$ of the cases living in rural areas and in $46 \%(253 / 550)$ of the cases living in urban areas ( $\mathrm{p}=0.0001)$. In a study conducted in South Africa, anti-HEV seropositivity was $6.6 \%$ in the urban area; It has been determined as $15.3 \%$ in rural areas. It has been reported that this rate is statistically significant, drinking water in rural areas is provided from the river without chlorination and this increases the risk of getting HEV infection [49]. In a study conducted in 2012 in urban and rural areas in Tunisia, seropositivity was found to be $9.6 \%$ in rural areas, $8.2 \%$ in high-density and lowincome areas in the city, and $1.7 \%$ in economically developed areas [35].

Seropositivity was observed in $69.2 \%(115 / 166)$ of the patients with cirrhosis in our study ( $\mathrm{p}=0.0001)$. Cirrhosis incidence rates in the study groups were found as $14.4 \%$ in the lowest HBV and $67.5 \%$ in HDV the highest ( $p=0.001$ ). Further studies are needed to determine whether a significantly higher rate of HEV seropositivity in cirrhotic patients with HDV has an effect on the severity and progression of the disease due to HDV.

In conclusion, epidemiological, clinical and laboratory parameters of 1025 patients who were examined retrospectively were analyzed in this study, which was carried out to determine the frequency of $\mathrm{HEV}$ in patients with viral hepatitis in our region in comparison with the control group.

Anti-HEV IgG seropositivity rate was 56.4\% (578/1025) in all patients. This rate was found to be higher than other studies conducted both in our region and in our country. In the study groups, seropositivity rates were $50 \%(142 / 284)$ in HBV patients, $70.7 \%$ (58/82) in HDV patients, 76.3\% (29/38) in HCV patients, and $56.2 \%(349 / 621)$ in the control group. With this study, a significantly higher rate of HEV seropositivity was observed in HCV and HDV-derived viral hepatitis patients in our region compared to the control group. In the study groups, the highest seropositivity was found in patients with HCV. In addition, a significantly higher rate of HEV seropositivity was found in cirrhotic patients with HDV. It is thought that this situation may affect the severity and progression of the disease due to HDV. Further studies are needed on this subject. 
Considering the factors causing high seropositivity; Improving the socioeconomic level, applying hygiene rules and raising the education level are important measures that can be taken.

In this study, it was found that HEV infection is more common in people with low education levels in our region, people living in rural areas, elderly people, married people, those who are engaged in animal husbandry, and cirrhotic patients. In addition, ALT and GGT elevation, low platelets, anti-delta positive, anti-HCV positive and anti-HAV IgG positive were determined as risk factors for seropositivity in logistic regression analysis. These demographic findings may contribute to the determination of risky patients and taking preventive measures in the control of HEV infection. Accurate and permanent anatomy education provides the ability to comment $85 \%$ on all diseases. Therefore, in studies belonging to researchers; anatomy is important.

\section{Bibliography}

1. Pilmane M., et al. "Embriology and Anatomy for Healthy Sciences". Riga Stradins University, Riga, Latvia (2016).

2. Aggarwal R and Naik S. "Epidemiology of hepatitis E: Current status". Journal of Gastroenterology and Hepatology 24 (2009): 1484-1493.

3. Thomas DL., et al. "Epidemiology of hepatitis E virus infection in Turkey”. Lancet 341 (1993): 1561-1562.

4. Khuroo MS. "Discovery of hepatitis E: the epidemic non-A, non-B hepatitis 30 years down the memory lane". Virus Research 161.1 (2011): 3-14.

5. Balayan MS., et al. "Evidence of a virus in non-A, non-B hepatitis transmitted via the fecal oral route". Intervirology 20.1 (1983): 23-31.

6. Reyes GR., et al. "Isolation of a cDNA from the virus responsible for enterically transmitted non-A, non-B hepatitis". Science 247.4948 (1990): 1335-1339.

7. Tam AW., et al. "Hepatitis E virus (HEV): molecular cloning and sequencing of the full-length viral genome". Virology 185 (1991): 120-131.

8. Vishwanathan R. "Infectious hepatitis in Delhi (1955-56): a critical study: epidemiology". Indian Journal of Medical Re- search 45 (1957): 1-29.

9. Khuroo MS. "Study of an epidemic of non-A, non-B hepatitis: possibility of another human hepatitis virus distinct from post-transfusion non- A, non-B type". American Journal of Medicine 68 (1980): 818-823.

10. Kamar N., et al. "Hepatitis E”. Lancet 379.9835 (2012): 24772488.

11. Panda SK and Varma SP. "Hepatitis E: molecular virology and pathogenesis". Journal of Clinical and Experimental Hepatology 3.2 (2013): 114-124.

12. Cao D and Meng XJ. "Molecular biology and replication of hepatitis E virus". Emerging Microbes and Infections 1.8 (2012): e17.

13. Yamashita T., et al. "Biological and immunological characteristics of hepatitis E virus-like particles based on the crystal structure". Proceedings of the National Academy of Sciences of the United States of America 106 (2009): 12986-12991.

14. Krain LJ., et al. "Host immune status and response to hepatitis E virus infection”. Clinical Microbiology Reviews 27.1 (2014): 139-165.

15. Nan Y., et al. "Hepatitis E virus inhibits type I interferon induction by ORF1 products". Journal of Virology 88.20 (2014): 11924-11932.

16. Ahmad I., et al. "Molecular virology of hepatitis E virus". Virus Research 161 (2011): 47-58.

17. Lu L., et al. "Phylogenetic analysis of global hepatitisE virus sequences: genetic diversity, subtypes and zoonosis". Reviews in Medical Virology 16 (2006): 5-36.

18. Huang CC., et al. "Molecular cloning and sequencing of the Mexico isolate of hepatitis E virus (HEV)". Virology 191.2 (1992): 550-558.

19. Kwo PY., et al. "Acute hepatitis E by a new isolate acquired in the United States". Mayo Clinic Proceedings 72 (1997): 11331136.

20. Erker JC., et al. "A hepatitis E virus variant from the United States: molecular characterization and transmission in cynomolgus macaques". Journal of General Virology 80 (1990): 681690. 
21. Wang Y., et al. "A divergent genotype of hepatitis Evirus in Chinese patients with acute hepatitis". Journal of General Virology 80 (1990): 169-177.

22. Ahmed A., et al. "Mystery of hepatitis E virus: recent advances in its diagnosis and management". International Journal of Hepatology 2015 (2015): 872431.

23. Purdy MA., et al. "The molecular epidemiology of hepatitis E virus infection”. Virus Research 161.1 (2011): 31-39.

24. Kmush B., et al. "Epidemiology of hepatitis E in low- and middle-income countries of Asia and Africa". Seminar on Liver Disease 33.1 (2013): 15-29.

25. Dalton HR., et al. "Hepatitis E: an emerging infection in developed countries". Lancet Infectious Disease 8.11 (2008): 698709.

26. Pischke S., et al. "Hepatitis E in Germany--an under-reported infectious disease". Deutsches Ärzteblatt International 111.3536 (2014): 577-583.

27. Kalia M., et al. "Heparan sulfate proteoglycans are required for cellular binding of the hepatitis E virus ORF2 capsid protein and for viral infection". Journal of Virology 83.24 (2009): 12714-12724.

28. Yamada K., et al. "ORF3 protein of hepatitis E virus is essential for virion release from infected cells". Journal of General Virology 90 (2009): 1880-1891.

29. Chandra NS., et al. "Dynamics of HEV viremia, fecal shedding and its relationship with transaminases and antibody response in patients with sporadic acute hepatitis E". Virology Journal 7 (2010): 213.

30. Chandra V., et al. "Molecular biology and pathogenesis of hepatitis E virus". Journal of Bioscience 33.4 (2008): 451-464.

31. Kamar N., et al. "Hepatitis E virus infection". Clinical Microbiology Reviews 27.1 (2014): 116-138.

32. Zhang S., et al. "Clinical significance of anti-HEV IgA in diagnosis of acute genotype 4 hepatitis $\mathrm{E}$ virus infection negative for anti-HEV IgM". Digestive Diseases and Sciences 54.11 (2009): 2512-2518.
33. Gu Y., et al. "Structural basis for the neutralization of hepatitis E virus by a cross-genotype antibody". Cell Research 25.5 (2015): 604-620.

34. Wedermeyer H., et al. "Pathogenesis and treatment of hepatitis E virus infection". Gastroenterology 142.6 (2012): 13881397.e1.

35. Wu T., et al. "Specific cellular immune response in hepatitis E patients". Intervirology 51.5 (2008): 322-327.

36. Wedemeyer H., et al. "Immunopathogenesis of hepatitis E virus infection”. Seminars in Liver Disease 33.1 (2003): 71-78.

37. Pérez-Gracia MT., et al. "Hepatitis E: an emerging disease". Infection, Genetics and Evolution 22 (2014): 40-59.

38. Khuroo MS., et al. "Acut sporadic Non-A, Non-B hepatitis in İndia". American Journal of Epidemiology 118 (1983): 360-364.

39. Haagsma EB., et al. "Chronic hepatitis E virus infection in liver transplant recipients". Liver Transplantation 14.4 (2008): 547-553.

40. Behrendt P., et al. "The impact of hepatitis $\mathrm{E}$ in the liver transplant setting". Journal of Hepatology 61.6 (2014): 1418-1429.

41. Teshale EH., et al. "Evidence of person-to person transmission of hepatitis E virus during a large outbreak in Northern Uganda". Clinical Infectious Disease 50.7 (2010): 1006-1010.

42. Browne LB., et al. "Notes from the field: Hepatitis E Outbreak Among Refugees from South Sudan - Gambella, Ethiopia, April 2014-January 2015". MMWR 64.19 (2015): 537.

43. Huang FF., et al. "Detection by reverse transcription-PCR and genetic characterization of field isolates of swine hepatitis $\mathrm{E}$ virus from pigs in different geographic regions of the United States". Journal of Clinical Microbiology 40.4 (2002): 13261332.

44. Kumar S., et al. "Molecular detection and sequence analysis of hepatitis E virus in patients with viral hepatitis from North India". Diagnostic Microbiology and Infectious Disease 71.2 (2011): 110-117.

45. Darwish MA., et al. "High seroprevalance of hepatitis A, B, C and $E$ viruses in residents in an Egyptian village in The Nil 
Delta: a pilot study". American Society of Tropical Medicine and Hygiene 54.6 (1996): 554-558.

46. Clayson ET., et al. "Rates of hepatitis E virus infection and diseases among adolescents and adults in Kathmandu, Nepal". The Journal of Infectious Diseases 176.3 (1997): 763-766.

47. Lewis HC., et al. "Transmission routes and risk factors for autochthonous hepatitis E virus infection in Europe: a systematic review". Epidemiology Infection 138.2 (2010): 145-166.

48. Wong KH., et al. "Epidemiology of hepatitis A and hepatitis E infection and their determinants in adult chinese community in Hong Kong”. Journal of Medical Virology 72 (2004): 538-544.

49. Tucker TJ., et al. "Hepatitis E şn South Africa: Evidence for sporadic spread and increased seroprevalence in rural areas". Journal of Medical Virology 50 (1996): 117-119.

50. Houcine N., et al. "Seroprevalence of HEV infection in rural and urban populations, Tunisia”. Clinical Microbiology Infection I8 (2012): 119-121.

Volume 3 Issue 7 July 2021

(C) All rights are reserved by Vatan Kavak, et al. 